\title{
Twelve Percent of Hips With a Primary Cam Deformity Exhibit a Slip-like Morphology Resembling Sequelae of Slipped Capital Femoral Epiphysis
}

\author{
Christoph E. Albers MD, Simon D. Steppacher MD, Pascal C. Haefeli MD, \\ Stefan Werlen MD, Markus S. Hanke MD, Klaus A. Siebenrock MD, \\ Moritz Tannast MD
}

Published online: 2 December 2014

(C) The Association of Bone and Joint Surgeons (B) 2014

\begin{abstract}
Background In some hips with cam-type femoroacetabular impingement (FAI), we observed a morphology resembling a more subtle form of slipped capital femoral epiphysis (SCFE). Theoretically, the morphology in these hips should differ from hips with a primary cam-type deformity.

Questions/purposes We asked if (1) head-neck offset; (2) epiphyseal angle; and (3) tilt angle differ among hips with a slip-like morphology, idiopathic cam, hips after in situ pinning of SCFE, and normal hips; and (4) what is the prevalence of a slip-like morphology among cam-type hips?
\end{abstract}

One author (MT) has received funding from the Swiss National Science Foundation (SNSF).

All ICMJE Conflict of Interest Forms for authors and Clinical Orthopaedics and Related Research ${ }^{\circledR}$ editors and board members are on file with the publication and can be viewed on request. Clinical Orthopaedics and Related Research ${ }^{\mathbb{R}}$ neither advocates nor endorses the use of any treatment, drug, or device. Readers are encouraged to always seek additional information, including FDAapproval status, of any drug or device prior to clinical use. Each author certifies that his or her institution has approved the human protocol for this investigation and that all investigations were conducted in conformity with ethical principles of research.

Electronic supplementary material The online version of this article (doi:10.1007/s11999-014-4068-x) contains supplementary material, which is available to authorized users.

C. E. Albers ( $₫)$, S. D. Steppacher, P. C. Haefeli,

M. S. Hanke, K. A. Siebenrock, M. Tannast

Department of Orthopaedic Surgery, Inselspital, University

of Bern, Freiburgstrasse 3010 Bern, Switzerland

e-mail: christoph.albers@insel.ch

S. Werlen

Department of Radiology, Sonnenhof Clinic, Bern, Switzerland
Methods We retrospectively compared the three-dimensional anatomy of hips with a slip-like morphology (29 hips), in situ pinning for SCFE (eight hips), idiopathic cam deformity (171 hips), and 30 normal hips using radial MRI arthrography. Normal hips were derived from 17 asymptomatic volunteers. All other hips were recruited from a series of 277 hips (243 patients) seen at a specialized academic hip center between 2006 and 2010. Forty-one hips with isolated pincer deformity were excluded. Thirtysix of 236 hips had a known cause of cam impingement (secondary cam), including eight hips after in situ pinning of SCFE (postslip group). The 200 hips with a primary cam were separated in hips with a slip-like morphology (combination of positive fovea sign [if the neck axis did not intersect with the fovea capitis] and a tilt angle [between the neck axis and perpendicular to the basis of the epiphysis] exceeding $4^{\circ}$ ) and hips with an idiopathic cam. We evaluated offset ratio, epiphyseal angle (angle between the neck axis and line connecting the center of the femoral head and the point where the physis meets the articular surface), and tilt angle circumferentially around the femoral head-neck axis. Prevalence of slip-like morphology was determined based on the total of 236 hips with cam deformities.

Results Offset ratio was decreased anterosuperiorly in idiopathic cam, slip-like, and postslip (eg, 1 o'clock position with a mean offset ranging from 0.00 to 0.14 ; $\mathrm{p}<0.001$ for all groups) compared with normal hips $(0.25 \pm 0.06$ [95\% confidence interval, 0.13-0.37]) and increased posteroinferiorly in slip-like (eg, 8 o'clock position, $0.5 \pm 0.09$ [0.32-0.68]; $\mathrm{p}<0.001$ ) and postslip groups $(0.55 \pm 0.12[0.32-0.78] ; \mathrm{p}<0.001)$ and did not differ in idiopathic cam $(0.32 \pm 0.09$ [0.15-0.49]; $\mathrm{p}=0.323)$ compared with normal $(0.31 \pm 0.07$ [0.18-0.44]) groups. Epiphyseal angle was increased anterosuperiorly in the 


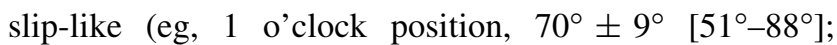
$\mathrm{p}<0.001)$ and postslip groups $\left(75^{\circ} \pm 13^{\circ}\left[49^{\circ}-100^{\circ}\right]\right.$; $\mathrm{p}=0.008)$ and decreased in idiopathic cam $\left(50^{\circ} \pm 8^{\circ}\right.$ $\left.\left[35^{\circ}-65^{\circ}\right] ; \quad \mathrm{p}<0.001\right)$ compared with normal hips $\left(58^{\circ} \pm 8^{\circ}\left[43^{\circ}-74^{\circ}\right]\right)$. Posteroinferiorly, epiphyseal angle was decreased in slip-like (eg, 8 o'clock position, $\left.54^{\circ} \pm 10^{\circ}\left[34^{\circ}-74^{\circ}\right] ; \mathrm{p}<0.001\right)$ and postslip $\left(44^{\circ} \pm 11^{\circ}\right.$ $\left.\left[23^{\circ}-65^{\circ}\right] ; \mathrm{p}<0.001\right)$ groups and did not differ in idiopathic cam $\left(76^{\circ} \pm 8^{\circ}\left[61^{\circ}-91^{\circ}\right] ; \mathrm{p}=0.099\right)$ compared with normal $\left(73^{\circ} \pm 7^{\circ}\left[59^{\circ}-88^{\circ}\right]\right)$ groups. Tilt angle increased in slip-like (eg, $2 / 8$ o' $^{\prime}$ clock position, $14^{\circ} \pm 8^{\circ}$ $\left[-1^{\circ}\right.$ to $\left.\left.30^{\circ}\right] ; \mathrm{p}<0.001\right)$ and postslip hips $\left(29^{\circ} \pm 10^{\circ}\right.$ $\left.\left[9^{\circ}-48^{\circ}\right] ; \mathrm{p}<0.001\right)$ and decreased in hips with idiopathic cam $\left(-7^{\circ} \pm 5^{\circ}\left[-17^{\circ}\right.\right.$ to $\left.\left.4^{\circ}\right] ; \mathrm{p}<0.001\right)$ compared with normal $\left(-1^{\circ} \pm 5^{\circ}\left[-10^{\circ}\right.\right.$ to $\left.\left.8^{\circ}\right]\right)$ hips. The prevalence of a slip-like morphology was $12 \%$.

Conclusions The slip-like morphology is the second most frequent pathomorphology in hips with primary cam deformity. MRI arthrography of the hip allows identifying a slip-like morphology, which resembles hips after in situ pinning of SCFE and distinctly differs from hips with idiopathic cam. These results support previous studies reporting that SCFE might be a risk factor for cam-type FAI.

Level of Evidence Level III, prognostic study.

\section{Introduction}

Slipped capital femoral epiphysis (SCFE) is a condition in childhood in which the femoral epiphysis is tilted posteroinferiorly. As a result, there is a loss of normal concavity of the anterior head-neck junction and the metaphyseal bone becomes exposed anterosuperiorly, creating a roughened surface (Fig. 1). On the posterior side, the slip leads to increased offset of the femoral head-neck junction. The anterior asphericity often leads to a cam-type femoroacetabular impingement (FAI) and substantial damage of the cartilage and labrum resulting in hip pain and, if left untreated, progression of osteoarthritis [2, 5, 10, 18, 24].

Based on our experience with surgical hip dislocation in open capital realignment for SCFE [25, 26], we have observed a similar intraoperative appearance in some cases of cam-type FAI potentially resembling a more subtle form of SCFE (Fig. 1). Such a slip-like morphology has already been described in previous studies based on an osteologic collection [7] or conventional radiographs [13, 15]. Drawbacks of these studies included lack of clinical information [7], a potential influence of secondary degenerative changes [14], and/or the use of two-dimensional (2-D) plain radiography $[13,14]$ to evaluate a threedimensional (3-D) problem.

We therefore evaluated the 3-D anatomy of the proximal femur based on MRI in hips with a slip-like morphology.
Fig. 1A-D In hips with (A) an idiopathic cam deformity, loss of normal concavity is the result of an extension of the epiphysis and bony protrusion (dashed line). Some hips with a cam deformity present with findings resembling those in hips with SCFE, which include a cleft resulting from the slipped epiphysis and a roughened metaphyseal surface (arrow). In the (B) AP pelvic radiograph, all hips present with a loss of the superior concavity. In the (C) axial view, the hips differ in terms of posterior tilt of the epiphysis: hips with an idiopathic cam deformity showed no tilt; hips with a slip-like morphology showed posterior tilting of the epiphysis; and hips with a postslip morphology showed most pronounced tilting of the epiphysis in relation to the femoral-neck axis (dashed line). In the (D) MRI arthrography, hips with an idiopathic cam deformity showed an extended epiphysis (dotted line) in the anterosuperior head-neck area. In contrast, hips with a slip-like or postslip morphology showed no extension of the epiphysis but a step resulting from slipping of the epiphysis (arrow).

Theoretically, these hips would resemble the anatomy of hips after in situ pinning for SCFE and differ from hips with a primary cam-type deformity. We specifically asked whether (1) the femoral head-neck offset; (2) epiphyseal angle; and (3) tilt angle differ among hips with a slip-like morphology, idiopathic cam deformity, normal hips, and hips with previous in situ pinning for SCFE; and (4) what is the prevalence of a slip-like morphology among symptomatic hips with a cam-type deformity?

\section{Materials and Methods}

We retrospectively compared the 3-D femoral head-neck anatomy using radial MRI arthrography among four groups: an idiopathic cam, slip-like morphology, postslip, and normal group (Table 1). The allocation to each group was based on the anatomy in the MRI arthrography and documented hip pathology or treatment. All hips except the hips in the normal group were recruited from 277 hips (243 patients) with symptomatic FAI and an MRI arthrography of the hip seen at the authors' outpatient clinic between January 2006 and March 2010 (Fig. 2). We excluded 41 hips (37 patients) with an isolated pincer-type FAI ( $\alpha$ angle $<50^{\circ}$ [17] on all radial MRI slices). Of the remaining 236 hips (206 patients) with a cam-type deformity, 36 hips (33 patients) had a known cause of cam deformity (secondary cam) identified by chart review (Fig. 2). These hips with a secondary cam included eight hips (seven patients) after in situ pinning for SCFE at a mean age of $12 \pm 1$ years (range, 10-14 years; postslip group; Fig. 2). The 200 hips (173 patients) with an unknown cause for the cam deformity (primary cam) were divided into two groups: the slip-like morphology group included 29 hips (26 patients) with radiographic criteria of an epiphyseal slip according to Goodman et al. [7] (combination of a tilt angle exceeding $4^{\circ}$ and a positive fovea sign and; see subsequently for description). The idiopathic cam group included the remaining 171 hips (147 patients) 


\section{Idiopathic Cam}
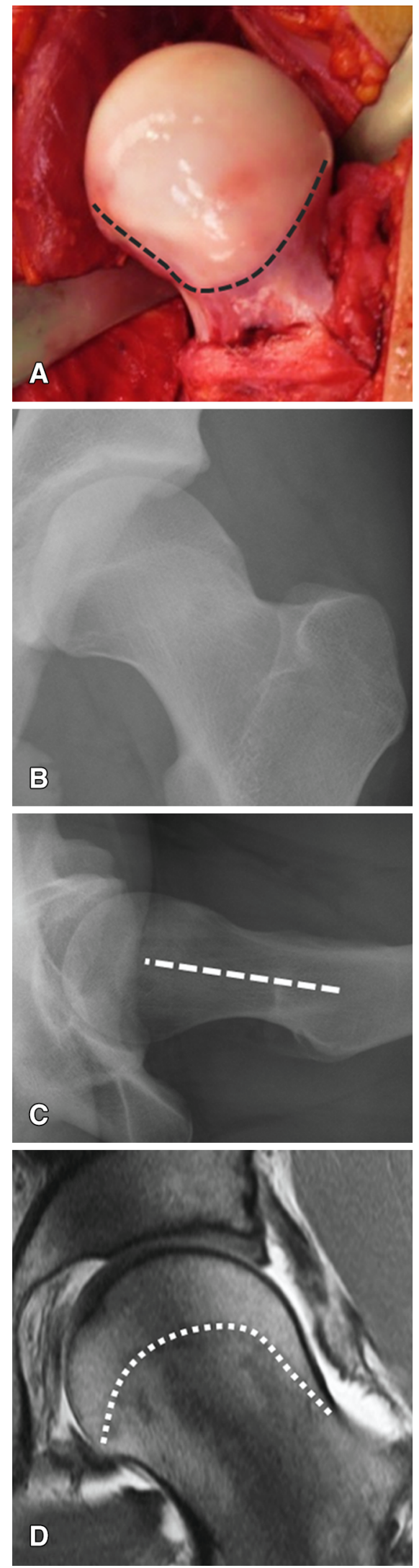

Slip-like Morphology
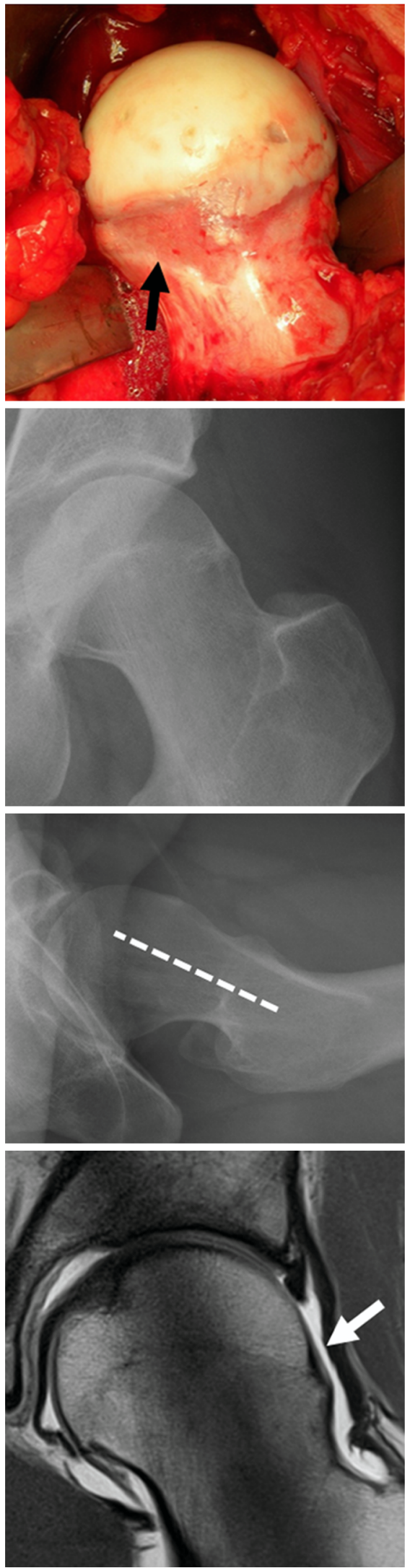

\section{Postslip Morphology}
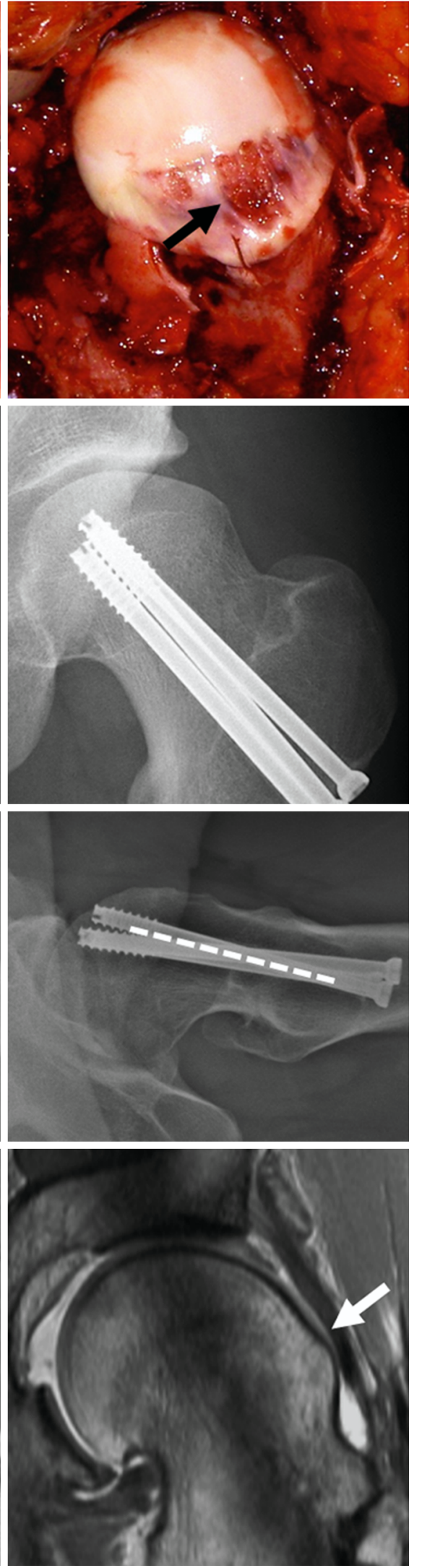
Table 1. Demographic and radiographic data for the four study groups

\begin{tabular}{|c|c|c|c|c|c|}
\hline \multirow[t]{2}{*}{ Factor } & \multicolumn{4}{|l|}{ Groups } & \multirow[t]{2}{*}{$\mathrm{p}$ value } \\
\hline & Idiopathic cam & Slip-like & Postslip & Normal hips & \\
\hline Number of hips (patients) & $171(147)$ & $29(26)$ & $8(7)$ & $30(17)$ & - \\
\hline Side (\% right of all hips) & 61 & 52 & 48 & 50 & 0.520 \\
\hline $\begin{array}{l}\text { Age at MRI (years) } \pm \mathrm{SD} \\
\quad \text { (range) }\end{array}$ & $25 \pm 6(13-37)^{*}$ & $24 \pm 6(16-34)^{\ddagger}$ & $25 \pm 8(17-43)^{*}$ & $17 \pm 2(15-20)^{* \dagger}$ & $<0.001$ \\
\hline Gender ( $\%$ men of all hips) & 59 & 72 & 25 & 53 & 0.096 \\
\hline Weight $(\mathrm{kg}) \pm \mathrm{SD}$ (range) & $73 \pm 13(45-105)^{*}$ & $82 \pm 15(58-105)^{\ddagger}$ & $75 \pm 25(60-130)$ & $66 \pm 14(48-95)^{*}$ & 0.011 \\
\hline Height $(\mathrm{m}) \pm \mathrm{SD}$ (range) & $1.74 \pm 0.09(1.53-1.99)$ & $1.77 \pm 0.07(1.65-1.90)$ & $1.73 \pm 0.12(1.62-1.98)$ & $1.74 \pm 0.08(1.56-1.87)$ & 0.618 \\
\hline $\begin{array}{l}\text { Body mass index }\left(\mathrm{kg} / \mathrm{m}^{2}\right) \\
\quad \pm \mathrm{SD} \text { (range) }\end{array}$ & $24 \pm 3.7(17-39)^{*}$ & $26 \pm 4.5(19-34)^{*}$ & $25 \pm 4.3(20-33)$ & $22 \pm 3.4(18-28)^{*}$ & $<0.001$ \\
\hline $\begin{array}{l}\text { Tilt angle at } 2 \text { o'clock } \\
\text { position }\left(^{\circ}\right) \pm \mathrm{SD} \\
\text { (range) }[21]\end{array}$ & $-7 \pm 5(-26 \text { to } 2)^{*, \dagger, *}$ & $14 \pm 8(4-39)^{*}$ & $29 \pm 10(10-38)^{\ddagger}$ & $-5 \pm 5(-13 \text { to } 4)^{* \dagger}$ & $<0.001$ \\
\hline $\begin{array}{l}\text { Fovea sign ( } \% \text { positive } \\
\text { of all hips) [7] }\end{array}$ & $3^{* \dagger}+$ & $100^{*}$ & $100^{*}$ & $0^{*}, \dagger$ & $<0.001$ \\
\hline
\end{tabular}

* Significant difference versus slip-like group; ${ }^{\dagger}$ significant difference versus postslip group; ${ }^{*}$ significant difference versus normal hips.

with a primary cam without radiographic evidence of an epiphyseal slip (Fig. 2). The normal group consisted of a previously published patient series [8] of 30 normal hips in 17 asymptomatic volunteers who underwent a radial MRI of the hip. The four study groups differed in terms of age at the acquisition of the MRI, weight, and body mass index (BMI) (Table 1). The normal group showed a decreased age (17 \pm 2 [range, 15-20] years) compared with the other study groups (mean age ranging from 24 to 25 years; $p$ ranging from $<0.001$ to 0.002$)$. In the normal group, both weight $(66 \pm 14$ [48-95] kg) and BMI (22 \pm 3.4 [18-28] $\mathrm{kg} / \mathrm{m}^{2}$ ) were decreased compared with the idiopathic cam ( $\mathrm{p}=0.028$ and $\mathrm{p}=0.002$, respectively) and slip-like group (both $\mathrm{p}=0.001$; Table 1 ). The study was approved by the local institutional review board.

All MRI arthrographies were performed according to a standardized protocol [11] on a 1.5- or 3-Tesla highfield scanner (Siemens Medical Solutions, Erlangen, Germany) with a flexible surface coil. All hips, except the normal hips, received intraarticular injection of gadolinium contrast agent (Dotarem 1:200, Guerbert AG, Paris, France). A proton density-weighted sequence was oriented radially around the femoral-neck axis, allowing circumferential measurements. The clockface system was applied for orientation around the femoral-neck axis (Fig. 3). Six o'clock was defined in line with the femoral shaft and 12 o'clock as the opposite position. Anterior was defined as 3 o'clock in both right and left hips. The subsequent slices were defined in clockwise and counterclockwise directions around the femoral head-neck axis for right and left hips, respectively (Fig. 3).

All MRI measurements were performed with commercially available DICOM-viewer JiveX (Version 4.5; VISUS Technology Transfer GmbH, Bochum, Germany). To differentiate between a slip-like deformity and idiopathic cam, two criteria according to Goodman et al. [7] were used; the tilt angle was constructed by the femoral neck axis and the perpendicular to the basis of the epiphysis (Fig. 4) on the radial MRI slice at the 2 o'clock position (most sensitive position to detect an epiphyseal slip in the posteroinferior direction [21]). A positive tilt angle indicates a posterior slip of the epiphysis. Goodman et al. [7] found a slip angle in normal hips ranging from $-5^{\circ}$ to $3^{\circ}$, whereas in hips with a SCFE, the tilt angle ranged from $5^{\circ}$ to $78^{\circ}$. Based on these two nonoverlapping ranges of the epiphyseal tilt angle, we defined the threshold of $>4^{\circ}$ tilt angle for hips with a sliplike deformity. The fovea sign was considered positive if the femoral-neck axis did not intersect with the fovea capitis femoris indicating a slip of the femoral epiphysis (Fig. 4) [7]. The fovea sign was assessed on two axial slices of the MRI arthrography: one at the level of the cranial femoral neck just inferior to the head to define the femoral neck axis (Fig. 4). The neck axis was then superimposed to a second slice positioned more cranial at level of the largest extension of the fovea capitis femoris to evaluate the fovea sign (Fig. 4). Hips in the slip-like group had both a slip angle exceeding $4^{\circ}$ and a positive fovea sign.

Three-dimensional morphology of the femoral head was assessed using the MRI arthrographies of the hip and three radiographic parameters: the offset ratio, epiphyseal angle, and tilt angle (Fig. 5). All three parameters were assessed circumferentially around the femoral-neck axis for all four study groups. The offset was evaluated using the offset ratio, which is a parameter to quantify the waist of the head-neck junction and can be used as an indicator of femoral head translation in relation to the femoral neck [6]. Offset ratio was calculated as the difference of the femoral 


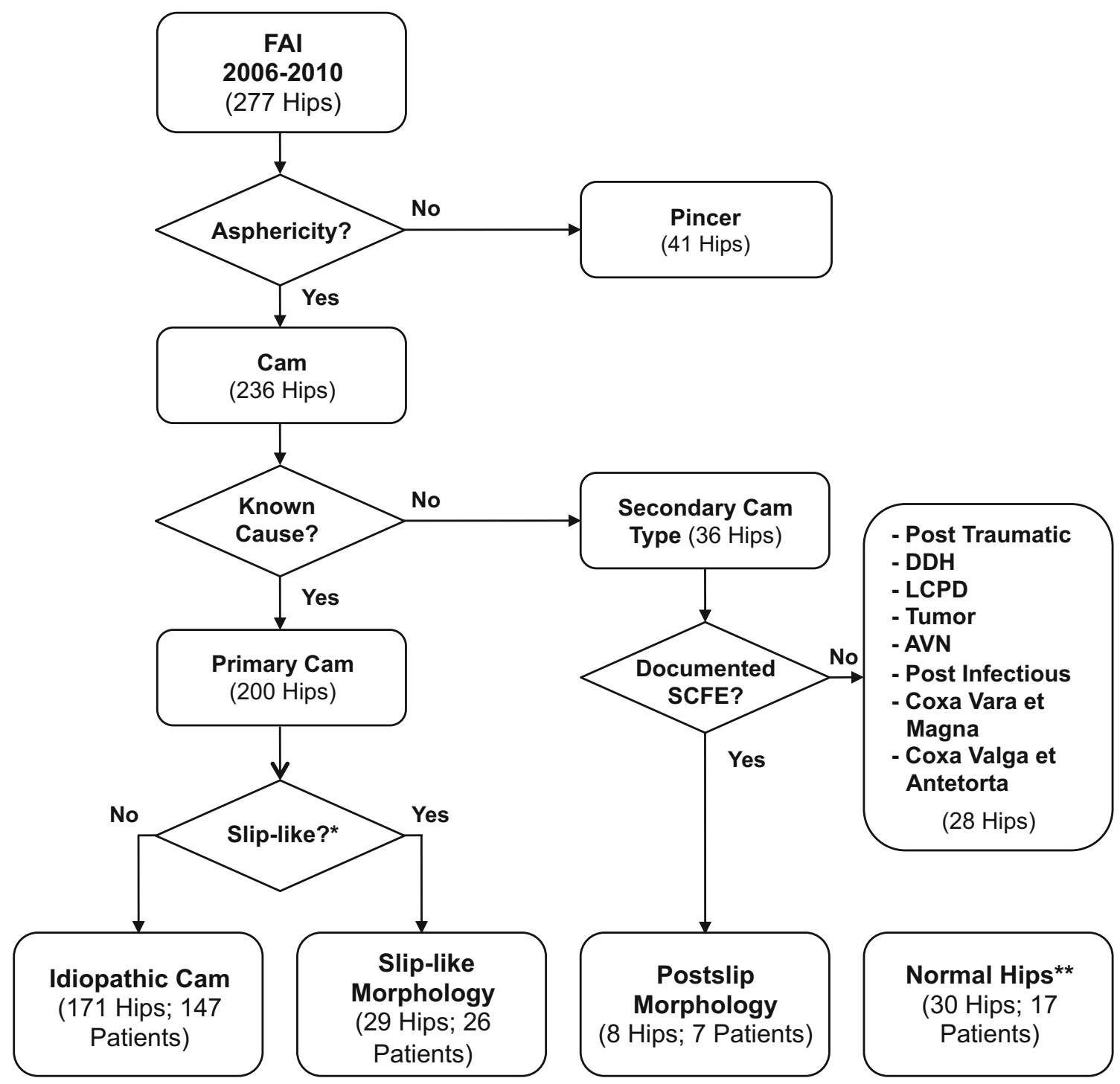

Fig. 2 Algorithm showing the selection process of the four study groups. *Defined by a positive fovea sign and a tilt angle exceeding $4^{\circ}[5]$. **Normal hips were recruited from a previously published series [6] of asymptomatic volunteers who underwent a radial MRI of

the hip. SCFE = slipped capital femoral epiphysis; DDH $=$ developmental dysplasia of the hip; LCPD = Legg-Calvé-Perthes disease; $\mathrm{AVN}=$ avascular necrosis.

head and neck radius divided by the head radius (Fig. 5) [3]. The true femoral-neck axis was determined independently from the center of the femoral head by the midpoint of two neck diameters (Fig. 5). [13] The epiphyseal angle can be used as a measure for head tilt or epiphyseal overgrowth [20]. It was constructed by the true femoralneck axis and a line through the center of the femoral head and the point where the physis meets the articular surface (Fig. 5) [22]. The tilt angle was measured as the angle between the true femoral-neck axis and perpendicular to the basis of the epiphysis (Fig. 5) [21]. The tilt angle was graded as mild with an angle $<30^{\circ}$, moderate between $30^{\circ}$ and $50^{\circ}$, and severe if $>50^{\circ}$ [21]. The reproducibility and reliability of the three applied MRI parameters were

determined on a set of 30 randomly chosen and blinded MRI slices evaluated by two observers (CEA, PCH) on two separate occasions. A good to very good reproducibility and reliability (intraclass correlation coefficient exceeding 0.6) was found for all three study parameters (Table 2).

The prevalence of hips with a slip-like morphology was determined in the series of 236 hips symptomatic hips (206 patients) with a cam deformity seen at our outpatient clinic (Fig. 2). Hip pathology (eg, Legg-Calvé-Perthes disease) and surgery (eg, in situ pinning for SCFE) were identified by chart review and anatomy (slip-like morphology or idiopathic cam) by MRI arthrography.

Normal distribution was assessed with the KolmogorovSmirnov test. Differences among the groups were assessed 


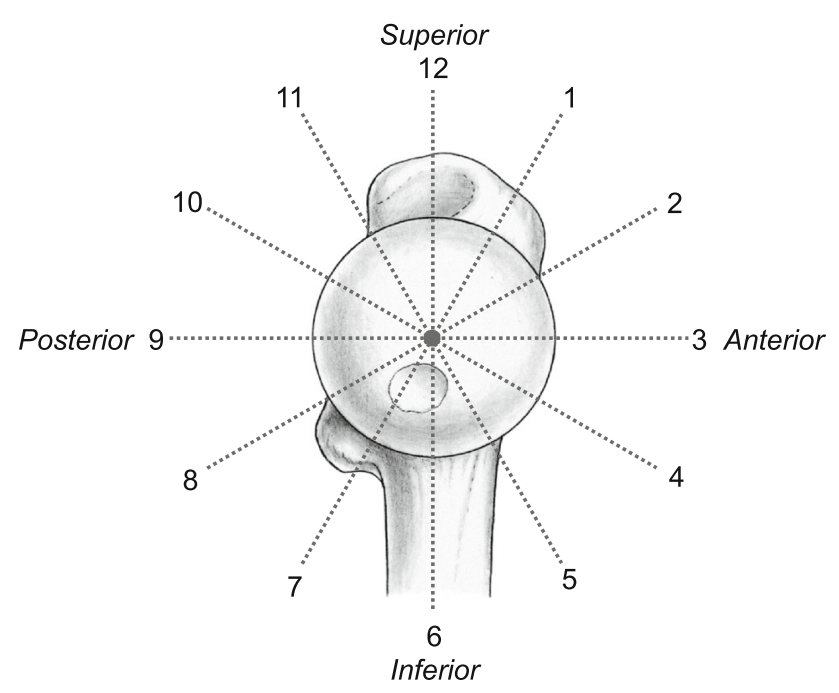

Fig. 3 An MRI arthrography of the hip with six radial slices rotating around the femoral head-neck axis was used for 3-D anatomic evaluation of the proximal femur. Offset and the epiphyseal angles were measured at all 12 positions. The tilt angle was determined on each of the six radial slices. Reprinted with kind permission from Springer Science+Business Media: Steppacher SD, Tannast M, Werlen S, Siebenrock KA. Femoral morphology differs between deficient and excessive acetabular coverage. Clin Orthop Relat Res. 2008;466:782-790; Fig. 3B.

using analysis of variance for normally distributed data and the Kruskal-Wallis test for nonnormally distributed data. If differences existed, pairwise comparison was performed with independent $\mathrm{t}$-tests for normally distributed data and with the Mann-Whitney $U$ test nonnormally distributed data with Bonferroni adjustment. Binominal data were assessed with the Fisher's exact test.

\section{Results}

The offset ratio differed anterosuperiorly from 12 to 3 o'clock and posteroinferiorly from 6 to 9 o'clock among the four groups (Supplemental Table 1 [Supplemental materials are available with the online version of $C O R R^{\circledR}$.]). Anterosuperiorly, the offset ratio was decreased in hips with an idiopathic cam deformity (eg, 1 o'clock position: $0.14 \pm 0.11[95 \%$ confidence interval $\{\mathrm{CI}\},-0.07$ to $0.35] ; \mathrm{p}<0.001)$ and lowest in hips with a slip-like morphology (eg, 1 o'clock position: $0.00 \pm 0.08[-0.15$ to $0.15] ; \mathrm{p}<0.001$ ) and a postslip deformity (eg, 1 o'clock position: $0.01 \pm 0.05 \quad[-0.09$ to 0.10$] ; \quad \mathrm{p}<0.001)$ compared with normal hips (eg, 1 o'clock position: $0.25 \pm 0.06$ [0.13-0.37]; Fig. 6A). Posteroinferiorly, the offset ratio was increased in hips with a slip-like morphology (eg, 8 o'clock position: $0.50 \pm 0.09$ [0.32-0.68]; $\mathrm{p}<0.001$ ) and postslip morphology (eg, 8 o'clock position: $0.55 \pm 0.12[0.32-0.78] ; \mathrm{p}<0.001)$ and did not
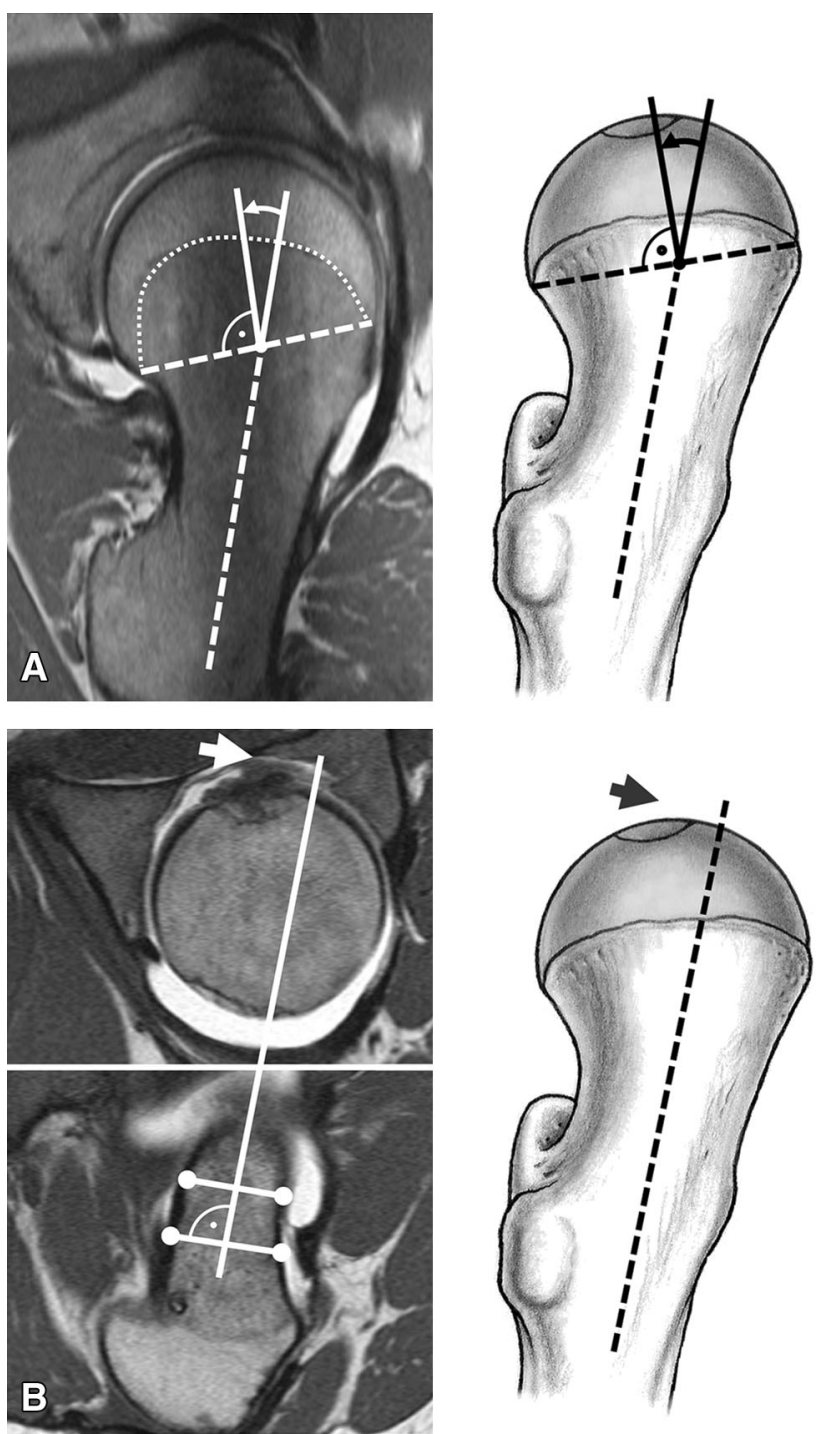

Fig. 4A-B A postslip morphology was differentiated from an idiopathic cam-type deformity using the two criteria according to Goodman et al. [7]: (A) a tilt angle exceeding $4^{\circ}$ and (B) a positive fovea sign. Both criteria were determined on the radial MRI slice at the 2 o'clock position. The tilt angle was constructed by the femoralneck axis and a perpendicular line to the line connecting the two ends of the femoral head physis. A positive tilt angle indicates a posterior slip of the epiphysis. The fovea sign was considered positive if the femoral-neck axis did not intersect with the fovea capitis femoris (arrow).

differ in hips with idiopathic cam (eg, 8 o'clock position: $0.32 \pm 0.09$ [0.15-0.49]; $\mathrm{p}=0.323$ ) compared with normal hips (eg, 8 o'clock position: $0.31 \pm 0.07$ [0.18-0.44]; Fig. 6A).

The epiphyseal angle differed anterosuperiorly from 12 to 3 o'clock and posteroinferiorly from 6 to 9 o'clock among the four study groups (Supplemental Table 2 [Supplemental materials are available with the online version of $\operatorname{CORR}^{\circledR}$.]). Anterosuperiorly, the epiphyseal angle was increased in hips with a slip-like morphology 


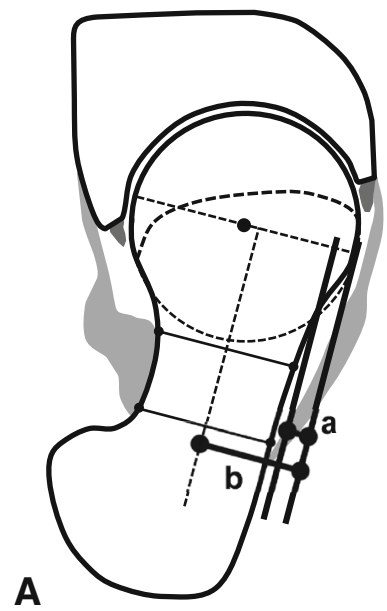

B

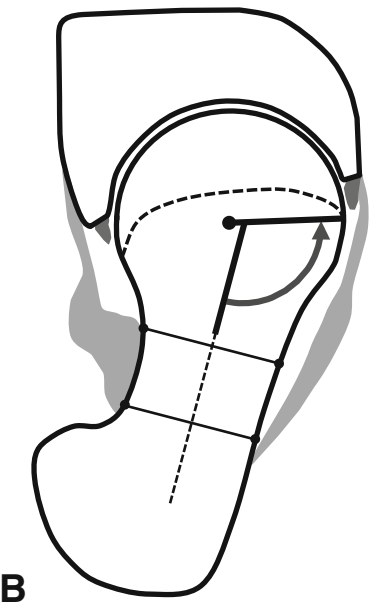

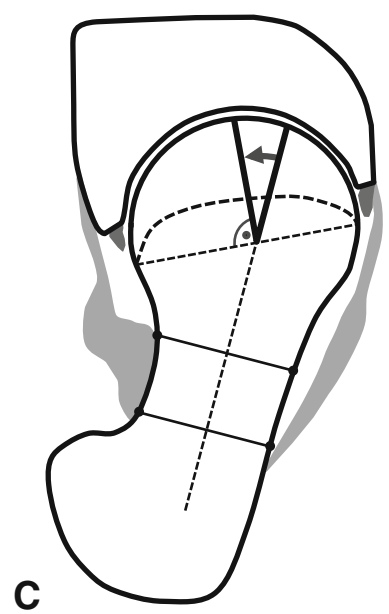

Fig. 5A-C The anatomy of the proximal femur was evaluated by three outcome parameters: offset ratio, epiphyseal angle, and tilt angle. (A) The offset ratio was calculated as the ratio of the difference of the femoral neck and head radius (a) divided by the femoral head radius (b). (B) The epiphyseal angle was formed by the femoral neck axis and a line through the femoral-head center and the point where the physis meets the head-neck surface. (C) The tilt angle was constructed by the femoral-neck axis and a perpendicular line to the line connecting the two ends of the femoral head physis.

Table 2. Reproducibility and reliability of evaluated MRI parameters.

\begin{tabular}{llll}
\hline Parameter & Intraobserver 1 ICC & Intraobserver 2 ICC & Interobserver ICC \\
\hline Head-neck offset* $[2]$ & $0.92(0.87-0.95)$ & $0.90(0.84-0.93)$ & $0.84(0.75-0.89)$ \\
Epiphyseal angle $\left({ }^{\circ}\right)^{*}[20]$ & $0.88(0.81-0.92)$ & $0.88(0.82-0.92)$ & $0.83(0.74-0.89)$ \\
Tilt angle $\left({ }^{\circ}\right)^{*}[19]$ & $0.94(0.89-0.97)$ & $0.81(0.64-0.90)$ & $0.71(0.49-0.84)$ \\
\hline
\end{tabular}

* Values are expressed as mean with $95 \%$ confidence interval in parentheses; ICC = intraclass correlation coefficient.

(eg, 1 o'clock position: $70^{\circ} \pm 9^{\circ}\left[95 \%\right.$ CI, 51 $\left.{ }^{\circ}-88^{\circ}\right]$; $\mathrm{p}<0.001)$ and postslip morphology (eg, 1 o'clock position: $\left.75^{\circ} \pm 13^{\circ}\left[49^{\circ}-100^{\circ}\right] ; \mathrm{p}=0.008\right)$ and decreased in hips with idiopathic cam deformities (eg, 1 o'clock position: $\left.50^{\circ} \pm 8^{\circ}\left[35^{\circ}-65^{\circ}\right] ; \quad \mathrm{p}<0.001\right)$ compared with normal hips (eg, 1 o'clock position: $58^{\circ} \pm 8^{\circ}\left[43^{\circ}-74^{\circ}\right]$; Fig. 6B). Posteroinferiorly, the epiphyseal angle was decreased in hips with a slip-like morphology (eg, 8 o'clock position: $\left.54^{\circ} \pm 10^{\circ}\left[34^{\circ}-74^{\circ}\right] ; \mathrm{p}<0.001\right)$ and postslip morphology (eg, 8 o'clock position: $44^{\circ} \pm 11^{\circ}$ $\left[23^{\circ}-65^{\circ}\right]$; $\left.\mathrm{p}<0.001\right)$ and did not differ in hips with idiopathic cam (eg, 8 o'clock position: $76^{\circ} \pm 8^{\circ}\left[61^{\circ}-91^{\circ}\right]$; $\mathrm{p}=0.099$ ) compared with normal hips (eg, 8 o'clock position: $73^{\circ} \pm 7^{\circ}\left[59^{\circ}-88^{\circ}\right]$; Fig. $6 \mathrm{~B}$ ).

The tilt angle differed from 12 to 3 o'clock among the study groups (Supplemental Table 3 [Supplemental materials are available with the online version of $C O R R^{\circledR}$.]). The tilt angle was increased in hips with a slip-like morphology (eg, $2 / 8$ o'clock position: $14^{\circ} \pm 8^{\circ}\left[95 \% \mathrm{CI},-1^{\circ}\right.$ to $30^{\circ}$ ]; $\mathrm{p}<0.001$ ) or postslip morphology (eg, $2 / 8$ o'clock position: $\left.29^{\circ} \pm 10^{\circ}\left[9^{\circ}-48^{\circ}\right] ; \mathrm{p}<0.001\right)$ and decreased in hips with idiopathic cam (eg, 2/8 o'clock position: $-7^{\circ} \pm 5^{\circ}\left[-17^{\circ}\right.$ to $\left.\left.4^{\circ}\right] ; \mathrm{p}<0.001\right)$ compared with normal hips (eg, 2/8 o'clock position: $-1^{\circ} \pm 5^{\circ}\left[-10^{\circ}\right.$ to $\left.8^{\circ}\right]$;

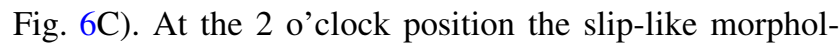
ogies were graded as mild slip (tilt angle $<30^{\circ}$ ) in 27 of 29 hips $(93 \%)$ and moderate slip (tilt angle from $30^{\circ}$ to $50^{\circ}$ ) in two of 29 hips (7\%) [21]. No hip was graded as severe slip (tilt angle $>50^{\circ}$ ) [21].

The prevalence of hips with a slip-like morphology in symptomatic hips with a cam-type deformity at a specialized academic hip center was 12\% (29 of 236 hips; Fig. 7).

\section{Discussion}

In the past two decades, FAI has gained increasing interest in both research and clinical practice as a cause of hip pain and as a prearthrotic deformity. However, the etiology of a cam-type deformity of the proximal femur is not yet fully understood. Although secondary cam deformities such as posttraumatic deformities [4], sequelae of Legg-CalvéPerthes disease [1, 23], or SCFE [2, 18, 24] have been identified, the majority of cam deformities are referred to as primary cam deformity. Based on our experience with surgical hip dislocation in open capital realignment for 

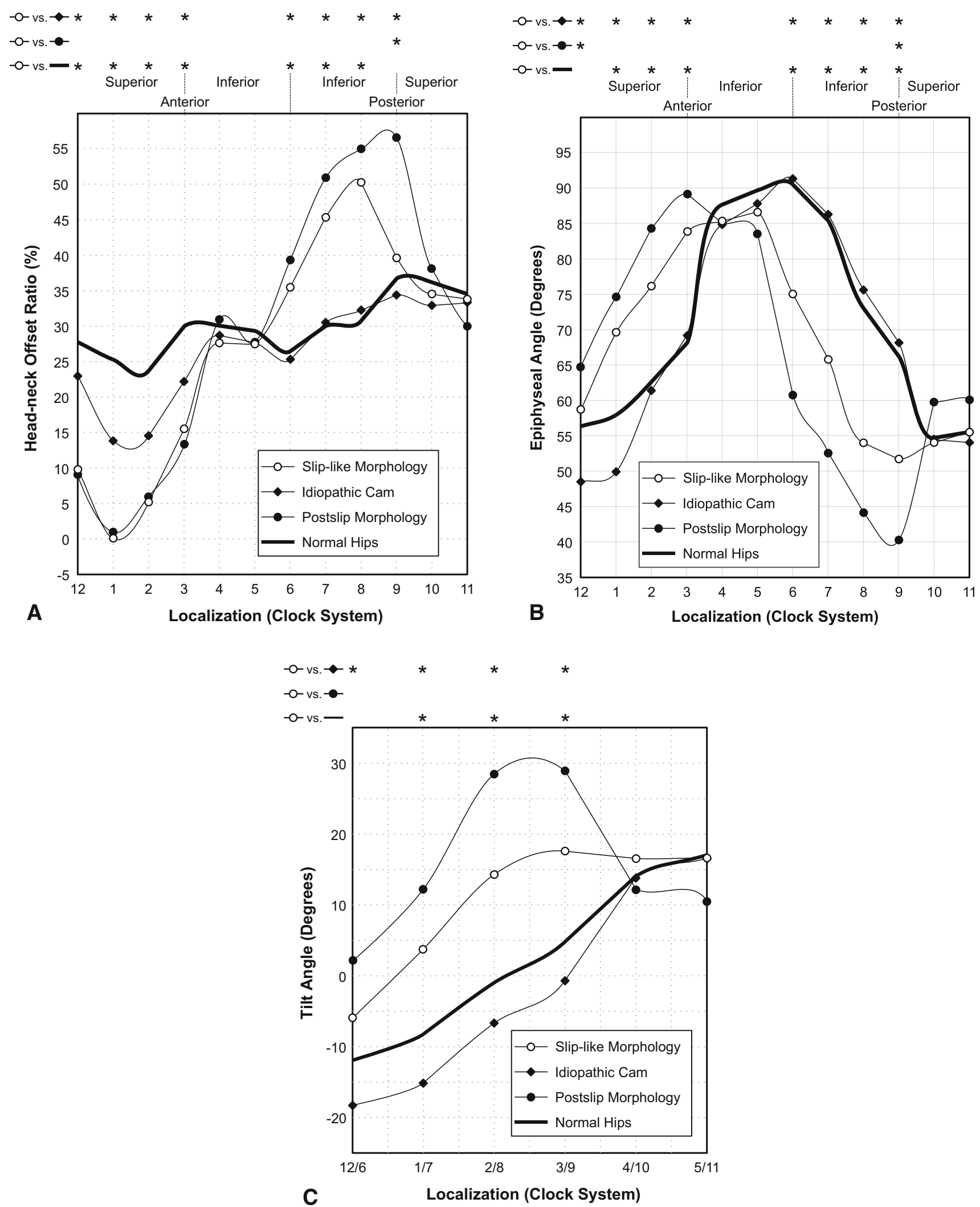

SCFE [25, 26], a similar slip-like appearance of the proximal femur was intraoperatively observed in some cases that were treated for primary cam-type FAI. This study therefore aimed to evaluate the 3-D anatomy of this sliplike morphology and its prevalence among hips with a primary cam deformity. We specifically asked if (1) the 
4Fig. 6A-C (A) Graph showing results of the offset ratio around the femoral-neck axis. Anterosuperiorly, the offset ratio was decreased in all study groups compared with the normal hip group; lowest values were in hips with a slip-like and postslip morphology. Posteroinferiorly, the offset ratio was increased in hips with a slip-like and postslip morphology compared with normal hips or hips with an idiopathic cam-type deformity (see also Supplemental Table 1). (B) Graph showing results of the epiphyseal angle around the femoral neck axis. Anterosuperiorly, the epiphyseal angle was increased in hips with a slip-like and postslip morphology and decreased in hips with idiopathic cam-type morphology compared with the normal group. Posteroinferiorly, the epiphyseal angle was decreased in hips with a slip-like and postslip morphology compared with normal hips or hips with idiopathic cam-type deformity (see also Supplemental Table 2). (C) Graph showing results of the epiphyseal tilt angle around the femoral-neck axis. The epiphyseal tilt angle differed among the four study groups anterosuperiorly from 12 to 3 o'clock. Although hips with a slip-like and postslip morphology showed the most pronounced epiphyseal tilt angle, tilt angle was lowest for hips with an idiopathic cam-type deformity (see also Supplemental Table 3).

femoral head-neck offset; (2) the epiphyseal angle; and (3) the tilt angle differed among hips with slip-like morphology, idiopathic cam deformity, postslip morphology after in situ pinning for SCFE, and normal hips. We also wanted to know (4) the prevalence of a slip-like morphology among hips with a cam-type deformity.

Our study has several limitations. First, we cannot prove that patients with a slip-like morphology with symptomatic cam-type FAI in fact did undergo prior SCFE. The goal of the current study was to describe the two most commonly found morphological variations in hips with a primary cam deformity. However, the fact that hips with a slip-like morphology exhibit similar morphological patterns compared with hips that underwent previous in situ pinning for SCFE (postslip group) indicates that there might have been previous SCFE. This is supported by the fact that normal hips and hips with an idiopathic cam deformity showed a distinctly different morphology (Fig. 8). Second, if hips with a slip-like morphology in fact did undergo prior epiphyseal slippage, we cannot assume that these hips had a clinically silent slip. This is mainly referred to recall bias, which is an unavoidable consequence of any retrospective study where the event in question occurs years before the evaluation of interest. Therefore, it cannot be postulated that hips with a slip-like morphology represent a new entity of cam-type FAI that differs distinctly from hips with previous in situ pinning of a documented SCFE (postslip group). Third, calculation of prevalence of the slip-like morphology was based on a population presenting at a specialized academic hip center and therefore is subject to selection bias. These patients were referred from a primary care physician or other orthopaedic centers and presented often with complex hip disorders. Therefore, SCFE and slip-like morphology may be overrepresented in our study population and generalization of the prevalence to the general population is not recommended.

Further limitations include the limited number of hips after in situ pinning for SCFE (postslip group). The

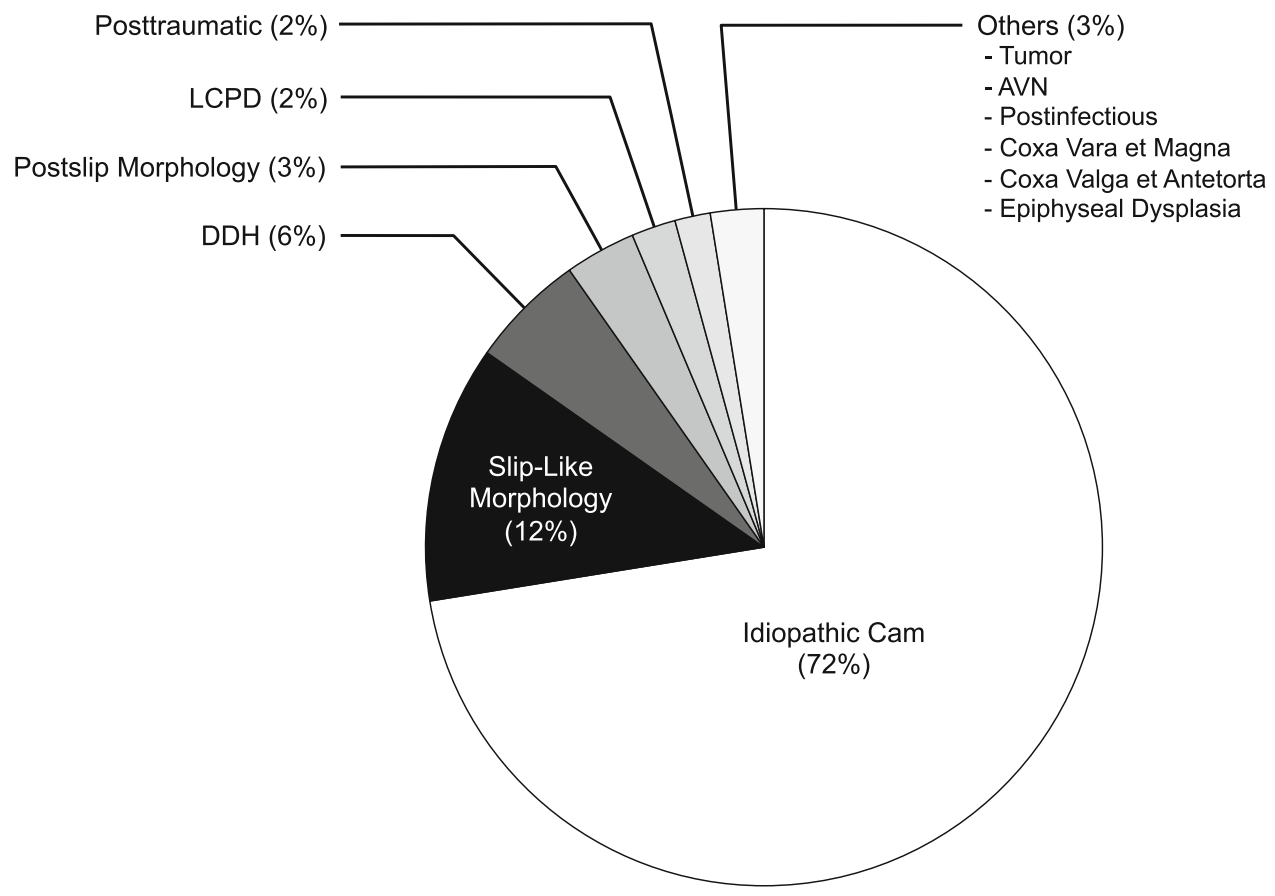

Fig. 7 Pie chart showing the prevalence of different cam-type deformities in hips from our study cohort. Hips with a postslip morphology showed the second highest prevalence of $12 \%$. The highest prevalence of $72 \%$ was found in hips with an idiopathic cam-type deformity. $\mathrm{LCPD}=$ Legg-Calvé-Perthes disease; $\mathrm{DDH}=$ developmental dysplasia of the hip; AVN = avascular necrosis. 


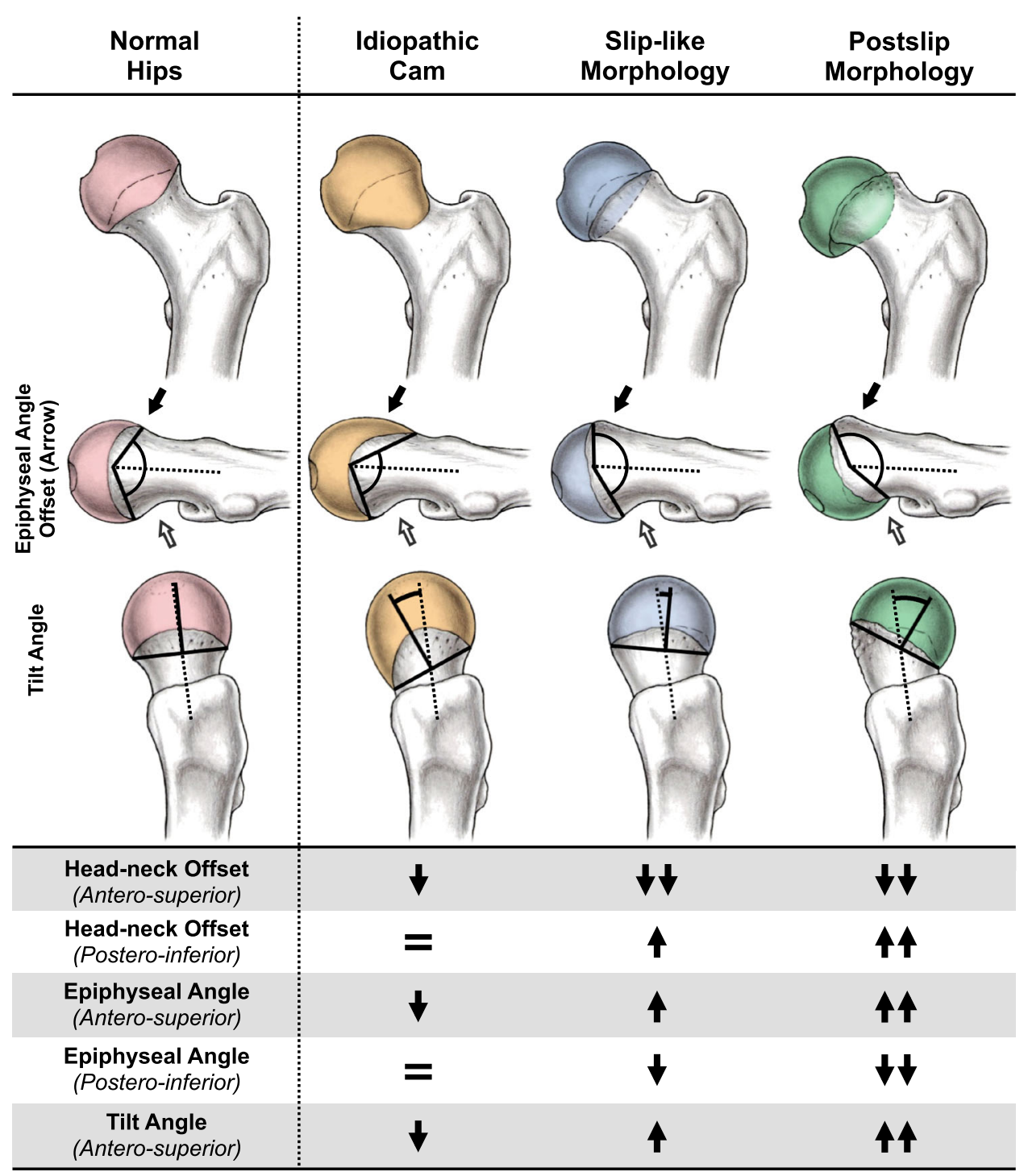

Fig. 8 Morphologic features of the proximal femur for the four study groups are shown.

resulting lack of statistical power might explain the lack of morphological differences in MRI outcome parameters between the slip-like and postslip group. Next, the normal group had a decreased age, decreased weight, and decreased BMI compared with the other study groups (Table 1). However, all normal hips had a closed physis. The youngest patient in the normal group was 15 years old, which is older than the reported average age at onset of SCFE, which is 12.7 years in males and 11.2 years in females $[9,12]$. Therefore, it is unlikely that we would have missed patients in the normal group, who had an epiphyseal slip at a later age. Finally, the definition to differentiate between the slip-like and idiopathic cam groups was based on two criteria (fovea sign and tilt angle) according to Goodman et al. [7]. He measured tilt of the head in relation to the neck with a goniometer in cadaver specimen and has not explicitly defined a threshold to differentiate normal tilt from that after slippage. We extrapolated this threshold as $>4^{\circ}$ tilt angle based on two not overlapping ranges of tilt angle for normal tilt and slip. Despite this relatively insensitive method to determine tilt, we found distinctive differences in the 3-D anatomy between the slip-like and idiopathic cam groups.

Femoral head-neck offset has been proposed as a measure of femoral-head translation in relation to the femoral neck, thus indicating "slipping" of the epiphysis (Fig. 8) [6]. Our data indicate that the hips with a slip-like morphology might indeed have undergone posteroinferior head translation as described in the literature [16]. Despite the 9 o'clock position with an increased offset in the postslip 
group, there were no differences in offset between hips with a slip-like morphology and hips with previous in situ pinning for a documented SCFE (postslip group) indicating a posteroinferior head translation in both groups (Fig. 6A). Idiopathic cam deformities also had a decreased anterior offset to a lesser extent than hips in the postslip or slip-like group; however, posterior offset was normal in hips with an idiopathic cam (Fig 6A). As suggested in the literature [20], our findings indicate that hips with an idiopathic cam deformity (idiopathic group) are more likely related to an isolated pathology of the anterior-femoral head-neck area rather than to epiphyseal translation.

Epiphyseal angles [22] were chosen as a study parameter to distinguish between epiphyseal slippage and abnormal physeal growth (Fig. 8). Epiphyseal angles of hips with a slip-like morphology were increased anterosuperiorly and decreased posteroinferiorly compared with normal hips and hips with idiopathic cam deformity (Fig. 6B). Compared with hips with previous in situ pinning for SCFE, the epiphyseal angles in hips with a sliplike morphology showed only minor differences (at the 9 and 12 o'clock positions), data that suggest posteroinferior tilting of the femoral epiphysis in relation to the metaphysis in hips with a slip-like morphology (Fig. 6B). We found a completely different pattern of the epiphyseal angles compared with idiopathic cam deformity. Idiopathic cam deformity typically presents with a normal epiphyseal angle in all quadrants except the anterosuperior quadrant, where a largely decreased epiphyseal angle was found (Fig. 6B). The finding was consistent with previous reports describing a pathologic extension of the anterior epiphysis in primary cam-type FAI [20]. The extension was attributed to a growth abnormality that can potentially be associated with vigorous sports activities [19].

The tilt angle showed a distinct pattern that potentially allows one to distinguish between hips with a slip-like morphology and hips with an idiopathic cam deformity with extension of the epiphysis (Fig. 8). Although the tilt angle is positive with posteroinferior epiphyseal slippage, it is negative in hips with an idiopathic cam deformity (Figs. 6C, 8). This effect is most pronounced in the anterosuperior quadrant of the femoral neck. It is very unlikely that the negative tilt angle in idiopathic cam hips is a result of an anterior epiphyseal slippage because the posterior epiphyseal angle is normal in these hips (Fig. 6B$\mathrm{C})$. The negative tilt angle in idiopathic cam hips most likely results from an abnormal overgrowth of the anterior epiphysis [20]. A mild slip (slip angle $<30^{\circ}$ [21]) was found in $93 \%$ of all hips with a slip-like deformity. This is comparable to the results of Goodman et al. [7] with $91 \%$ of all postslip deformities classified as mild slips.

Our data suggest that $15 \%$ of all cam deformities had features of previous SCFE; $12 \%$ of all hips with a cam deformity exhibited a slip-like morphology and 3\% had a cam deformity secondary to previous in situ pinning after SCFE (Fig. 7). Slip-like morphology was the second most often found pathomorphology in hips with cam-type morphology. There are several studies available describing the prevalence of a slip-like morphology for different study populations. A prevalence of $13 \%$ was found for healthy young adults [9]: $35 \%$ to $68 \%$ in hips with osteoarthritis requiring THA $[6,14]$ and $8 \%$ in anatomic specimens [7]. The only study investigating prevalence in hips with cam-type FAI without advanced osteoarthritis reported a prevalence of $44 \%$, which is higher than in our cohort [15]. The reason for this difference might be related to the use of a single parameter based only on 2-D radiographs in other studies.

Based on the 3-D analysis of femoral offset, epiphyseal angle, and tilt angle, we described a slip-like morphology among hips with primary cam deformities. We proposed MRI thresholds for the posterior offset ratio, the epiphyseal angle, and the tilt angle that allow for identifying this sliplike morphology within hips with a primary cam deformity (Supplemental Table 4 [Supplemental materials are available with the online version of $\mathrm{CORR}^{\circledR}$.]). As a topic of future research, these thresholds should be tested for validity. The slip-like morphology occurred in $12 \%$ of all cam deformities and differed from hips with an idiopathic cam deformity and normal hips. However, it resembled hips with a cam deformity secondary to previous in situ pinning of a documented SCFE. This morphological similarity indicates that there might have been prior SCFE and supports previous reports that have proposed SCFE as a risk factor for the development of cam-type FAI (Fig. 8) [2, 18, 24].

\section{References}

1. Albers CE, Steppacher SD, Ganz R, Siebenrock KA, Tannast M. Joint-preserving surgery improves pain, range of motion, and abductor strength after Legg-Calvé-Perthes disease. Clin Orthop Relat Res. 2012;470:2450-2461.

2. Castaneda P, Ponce C, Villareal G, Vidal C. The natural history of osteoarthritis after a slipped capital femoral epiphysis/the pistol grip deformity. J Pediatr Orthop. 2013;33:76-82.

3. Eijer H, Leunig M, Mohamed N, Ganz R. Cross-table lateral radiographs for screening of anterior femoral head-neck offset in patients with femoro-acetabular impingement. Hip Int. 2001;11:37-41.

4. Eijer H, Myers SR, Ganz R. Anterior femoroacetabular impingement after femoral neck fractures. J Orthop Trauma. 2001;15:475-481.

5. Fraitzl CR, Kafer W, Nelitz M, Reichel H. Radiological evidence of femoroacetabular impingement in mild slipped capital femoral epiphysis: a mean follow-up of 14.4 years after pinning in situ. $J$ Bone Joint Surg Br. 2007;89:1592-1596.

6. Giles AE, Corneman NA, Bhachu S, Rudan JF, Ellis RE, Grant H, Wood GC. Shared morphology of slipped capital femoral epiphysis and femoroacetabular impingement in early-onset arthritis. Orthopedics. 2013;36:1365-1370. 
7. Goodman DA, Feighan JE, Smith AD, Latimer B, Buly RL, Cooperman DR. Subclinical slipped capital femoral epiphysis. Relationship to osteoarthrosis of the hip. J Bone Joint Surg Am. 1997;79:1489-1497.

8. Kienle KP, Keck J, Werlen S, Kim YJ, Siebenrock KA, Mamisch TC. Femoral morphology and epiphyseal growth plate changes of the hip during maturation: MR assessments in a 1-year follow-up on a cross-sectional asymptomatic cohort in the age range of 917 years. Skeletal Radiol. 2012;41:1381-1390.

9. Lehmann CL, Arons RR, Loder RT, Vitale MG. The epidemiology of slipped capital femoral epiphysis: an update. J Pediatr Orthop. 2006;26:286-290.

10. Leunig M, Casillas MM, Hamlet M, Hersche O, Notzli H, Slongo T, Ganz R. Slipped capital femoral epiphysis: early mechanical damage to the acetabular cartilage by a prominent femoral metaphysis. Acta Orthop Scand. 2000;71:370-375.

11. Leunig M, Werlen S, Ungersbock A, Ito K, Ganz R. Evaluation of the acetabular labrum by MR arthrography. J Bone Joint Surg Br. 1997;79:230-234.

12. Loder RT. The demographics of slipped capital femoral epiphysis. An international multicenter study. Clin Orthop Relat Res. 1996;322:8-27.

13. Murgier J, Chiron P, Cavaignac E, Espie A, Bayle-Iniguez X, Lepage B. The lateral view head-neck index (LVHNI): a diagnostic tool for the sequelae of slipped capital femoral epiphysis. Orthop Traumatol Surg Res. 2013;99:501-508.

14. Murgier J, Espie A, Bayle-Iniguez X, Cavaignac E, Chiron P. Frequency of radiographic signs of slipped capital femoral epiphysiolysis sequelae in hip arthroplasty candidates for coxarthrosis. Orthop Traumatol Surg Res. 2013;99:791-797.

15. Murgier J, Reina N, Cavaignac E, Espie A, Bayle-Iniguez X, Chiron P. The frequency of sequelae of slipped upper femoral epiphysis in cam-type femoroacetabular impingement. Bone Joint J. 2014;96:724-729.

16. Murray RO. The aetiology of primary osteoarthritis of the hip. $\mathrm{Br}$ J Radiol. 1965;38:810-824.
17. Notzli HP, Wyss TF, Stoecklin CH, Schmid MR, Treiber K, Hodler J. The contour of the femoral head-neck junction as a predictor for the rick of anterior impingement. J Bone Joint Surg Br. 2002;84:556-560.

18. Saisu T, Kamegaya M, Segawa Y, Kakizaki J, Takahashi K. Postoperative improvement of femoroacetabular impingement after intertrochanteric flexion osteotomy for SCFE. Clin Orthop Relat Res. 2013;471:2183-2191.

19. Siebenrock KA, Ferner F, Noble PC, Santore RF, Werlen S, Mamisch TC. The cam-type deformity of the proximal femur arises in childhood in response to vigorous sporting activity. Clin Orthop Relat Res. 2011;469:3229-3240.

20. Siebenrock KA, Wahab KH, Werlen S, Kalhor M, Leunig M, Ganz R. Abnormal extension of the femoral head epiphysis as a cause of cam impingement. Clin Orthop Relat Res. 2004;418:5460.

21. Southwick WO. Osteotomy through the lesser trochanter for slipped capital femoral epiphysis. J Bone Joint Surg Am. 1967;49:807-835.

22. Steppacher SD, Tannast M, Werlen S, Siebenrock KA. Femoral morphology differs between deficient and excessive acetabular coverage. Clin Orthop Relat Res. 2008;466:782-790.

23. Tannast M, Hanke M, Ecker TM, Murphy SB, Albers CE, Puls M. LCPD: reduced range of motion resulting from extra- and intraarticular impingement. Clin Orthop Relat Res. 2012;470:2431-2440.

24. Wensaas A, Gunderson RB, Svenningsen S, Terjesen T. Femoroacetabular impingement after slipped upper femoral epiphysis: the radiological diagnosis and clinical outcome at long-term follow-up. J Bone Joint Surg Br. 2012;94:1487-1493.

25. Ziebarth K, Leunig M, Slongo T, Kim YJ, Ganz R. Slipped capital femoral epiphysis: relevant pathophysiological findings with open surgery. Clin Orthop Relat Res. 2013;471:2156-2162.

26. Ziebarth K, Zilkens C, Spencer S, Leunig M, Ganz R, Kim YJ. Capital realignment for moderate and severe SCFE using a modified Dunn procedure. Clin Orthop Relat Res. 2009;467:704716. 